\title{
A role for thiazide diuretic therapy in preventing bone loss, fracture, and nephrolithiasis in individuals with thalassemia and hypercalciuria?
}

\author{
A. Morton ${ }^{1}$
}

Received: 20 December 2016/Accepted: 10 January 2017 / Published online: 13 February 2017

(C) International Osteoporosis Foundation and National Osteoporosis Foundation 2017

\section{Dear Editor,}

I thank Dede et al. for their comprehensive review on the treatment of thalassemia-associated osteoporosis, noting the high prevalence of hypercalciuria and nephrolithiasis, and the association of the latter with lower femoral neck bone density and higher fracture rates in male patients [1]. A recent study demonstrated hypercalciuria was present in $92 \%$ of individuals with thalassemia treated with deferasirox in a positive dose-dependent relationship [2]. Thiazide diuretic use reduces urine calcium loss and is associated with improved bone density and reduced risk of hip fracture in observational studies [3]. In individuals with hypercalciuria and osteopenia/osteoporosis, administration of a thiazide or indapamide with bisphosphonate therapy was associated with greater reduction in calciuria and greater improvement in bone density than with bisphosphonate therapy alone [4, 5]. Studies examining the efficacy of thiazide or thiazide-like diuretics alone or in combination with bisphosphonates in improving bone density and reducing the risk of nephrolithiasis and fracture in individuals with thalassemia and hypercalciuria would be worthwhile.

A response to these comments can be found at doi: 10.1007/s00198-17$3927-1$.

\section{A. Morton}

Adam.morton@mater.org.au

University of Queensland and Mater Health, Raymond Tce, South Brisbane 4101, Australia
Compliance with ethical standards

Conflicts of interest None.

\section{References}

1. Dede AD, Trovas G, Chronopoulos E, Triantafyllopoulos IK, Dontas I, Papaioannou N, Tournis S (2016) Thalassemiaassociated osteoporosis: a systematic review on treatment and brief overview of the disease. Osteoporosis Int 27: 3409-3425. doi:10.1007/s00198-016-3719-Z

2. Wong P, Polkinghorne K, Kerr PG, Doery JC, Gillespie MT, Larmour I, Fuller PJ, Bowden DK, Milat F (2016) Deferasirox at therapeutic doses is associated with dosedependent hypercalciuria. Bone 85:55-58

3. Kruse C, Eiken P, Vestergaard P (2016) Continuous and long-term treatment is more important than dosage for the protective effect of thiazide use on bone metabolism and fracture risk. J Intern Med 279: 110-122

4. Giusti A, Barone A, Pioli G, Girasole G, Siccardi V, Palummeri E, Bianchi G (2009) Alendronate and indapamide alone or in combination in the management of hypercalciuria associated with osteoporosis: a randomized controlled trial of two drugs and three treatments. Nephrology, dialysis, transplantation: official publication of the European Dialysis and Transplant Association - European Renal Association 24: $1472-1477$

5. Arrabal-Polo MA, Arias-Santiago S, de Haro-Munoz T, LopezRuiz A, Orgaz-Molina J, Gonzalez-Torres S, Zuluaga-Gomez A, Arrabal-Martin M (2013) Effects of aminobisphosphonates and thiazides in patients with osteopenia/osteoporosis, hypercalciuria, and recurring renal calcium lithiasis. Urology 81 : $731-737$ 